\title{
The relationship between Emotional Intelligence and
}

\section{Thinking Styles in Male and Female Students in Tehran,}

\author{
Iran
}

\author{
Reza Norouzi Kouhdasht \\ Department of Educational administration, Science and Research Branch Islamic Azad \\ University, Tehran, Iran \\ Rezanorouzi1986@yahoo.com \\ Mohammad Jafar Mahdian \\ Faculty of Islamic Azad University Boroujerd Branch - Boroujerd, Iran \\ mjmahdian@yahoo.com \\ Mahboobeh Afzali Naeini \\ Department of Educational administration, Science and Research Branch Islamic Azad \\ University, Tehran, Iran
}

Accepted: May 18, 2013 Published: June 15, 2013

Doi:10.5296/ijld.v3i3.3865 URL: http://dx.doi.org/10.5296/ijld.v3i3.3865

\begin{abstract}
The present study attempts to examine the relationship between emotional intelligence and students' thinking styles in school district 13 of Tehran. The target population included all the high school students in this area 200 of which were selected for the purpose of this study. The method of this study was descriptive and correlational. The data were collected by field study and questionnaire. A questionnaire was used to measure the participants' emotional intelligence which had 19 questions. In order to investigate the participants' thinking styles, Sternberg and Wagner's thinking styles inventory was used which has 40 questions and measures five thinking styles (legislative, judicial, executive, outward, inward). The collected data were analyzed by SPSS software using descriptive (frequency, mean and standard deviation) and inferential statistics (Pearson correlation coefficient, chi2, dependent-samples $\mathrm{t}$-test). Reliability of the emotional intelligence questionnaire was found to be 0.78 . The results showed that there was a meaningful relationship between emotional intelligence and thinking styles of boy and girl students; there was a difference between boys and girls in thinking style; there was also a significant difference between the two groups in emotional intelligence. The results pointed to the conclusion that emotional intelligence can highly influence thinking style. Therefore, authorities are recommended to arrange for proper training and educational programs in this regard for students to help them control their emotional intelligence and take appropriate measures for selecting the right thinking style.
\end{abstract}

Key words: Emotional Intelligence, Thinking Style, Students 


\section{Introduction}

\subsection{Background of the study}

\subsubsection{Emotional intelligence: definition}

Traditionally, the future of individuals used to be planned based on their emotional intelligence, but during the recent years the situation has changed as a consequence of the many studies conducted in this regard. As Goleman (1995) states,personal and interpersonal skills have a larger importance than IQ in personal, social and professional situations people are involved in. He even claims that in the best state, individuals' intelligence and talent can only have a $20 \%$ role in individuals' success and the rest $(80 \%)$ is related to some other factors generally called emotional intelligence. Although emotional intelligence has been proposed in different shapes and forms during the history, the first contemporary definition of emotional intelligence was provided by Salovey in 1990. According to him, emotional intelligence is a type of processing of the emotional information including exact evaluation of the emotions in oneself and others, proper expression of feelings, and adaptive arrangement of emotions in a way that promotes living (Haghani\& et al., 2011). Some define emotional intelligence as the ability to understand the emotions and achieve the kind of emotions that not only help to think better but also prepare the ground for regulating the emotions and feelings and, consequently emotional and intellectual promotion. Emotional intelligence has five main components: self-awareness, self-motivation, controlling the feelings, social consciousness, and social skill. Theoristsbelieve that emotional intelligence can be a more reliable predictor of an individual's future. The important point about emotional intelligence is that it can be taught and fostered. Emotional intelligence refers to all the skills that form our emotional consciousness. Emotional intelligence skills bring persistence and stability against failure, promote the spirit, and repress feelings of disappointment and depression, and promote the bonding attitude in them. It not only develops the skill for building relationships with others but also helps individuals to perform better in different situations. All of us face problems and challenges in our lives, but each person deals with them using his/her own strategy. Some try to perform a correct and logical evaluation of the situation and deal with it using supportive strategies.In contrast, some other try toignore and avoid facing the problems using different methods such as taking alcohol, drugs and other inefficient strategies instead of face-to-face confrontation with the problems (Moshtaghzadeh, 2003). The feelings individuals have originate from their evaluation of the information coming from the surrounding environment. This evaluation includes knowledge and processing of the information gathered from the environment, body, memory, and willingness to respond in a special way, and observing the consequences of the actions that may follow a specific emotional state. Emotions influence and bring a special taste and color into our lives. Positive emotions like affection and enthusiasm make our lives full of affection and negative emotions such as depression and rage fill in us fear and terror making life difficult and intolerable (Zarean, 2007). Therefore, thoughts and understandings of an individual play an important role in determining which feelings provoke him/her (sakaki, 2002).

Almost all the ongoing behaviors and individuals' goal setting are influenced by emotions. In fact, purposeful behaviors are driven by motivations and make individuals attempt to achieve satisfaction and relief. Emotions drive our motivations (Goleman, 2011). The basic point is that studies on intelligence have been initially focused on the cognitive aspects such as memory and problem solving while non-cognitive, i.e. emotional and behavioral, aspects are not only acceptable but also essential (Goleman, 2010). In 1945,Wechsler proposed that non-cognitive abilities are important in predicting individual skills for future success in life. In other words, intellectual behavior is a combination of cognitive, social and emotional components. 


\subsubsection{The relationship between emotional intelligence and ability}

The process of becoming emotional is not limited to showing unhappiness or getting enjoyment in a systematic way but always subtly follows all our actions. People have understood the importance of this kind of interaction more than before. The concepts of emotional intelligence and social intelligence are examples of this type of interaction. Although differentiating between abilities and thinking styles is of a lot of significance in the area of thinking styles (Strenberg, 2001), thinking styles interact with the abilities. According to triarchic theory of intelligence, intelligent people are conceptually those who invest on their strengths and overcome or compensate for their weaknesses. A large part of this investment, overcoming, and compensation depends on the coordination between individual abilities and thinking styles that an individual preferably selects. Those who are not able to coordinateexperience failure due to lack of correspondence between how they like to act and how they can act.If at least a part of the thinking styles is more socially accepted, it should be certainly changeable to varying degrees. This changeability is not usually easy. Our knowledge about how thinking changes is much less than our knowledge of the changes in thinking styles, but we should train students to invest on their strengths and compensate for or overcome their weaknesses. Compensating for some shortcomings is possible but complete compensation is not practical. Compensation mechanisms are usually applied to fill in the gap between weaknesses and strengths in performance (Sternberg, 1997). Interest in understanding thinking styles is developed in part of the response to this type of understanding; common ability tests can partly answer the question why and how individuals are different from each other in their performance style. Individuals have understood the importance of this ability more than before and the concept of emotional intelligence is an example of this interaction. Although differentiating between abilities and thinking styles is important, emotional intelligence may be indicative of a set of abilities and thinking styles my indicate priorities. This differentiation is important because abilities may correspond with priorities (Sternberg, 1997). Emotional intelligence is a form of social intelligence and a predictor of overall efficiency and expediency in specific environments such as job performance which includes the ability to control one's and others' feelings and emotions, differentiating between them, and using this information for guiding one's thoughts and performance (Salovey\& Mayer, 1990). Since prosperity and prestige of a society depend on its training and education and individuals can have a greater or weaker presence and performance in different stages of their education and employment depending on to what extent their educational and occupational environment are consistent or inconsistent with their thinking style because social, emotional and performance structures of intelligence and in other words different aspects of intelligence form our image of what individuals can do and the structures related to thinking can get a probably closer to reality picture ofwhat individuals prefer. In tasks assigned to individuals, some considerations can be made to ensure that the task is matched with their thinking styles or their thinking styles are modified in accordance with the task. But if individuals are not efficient in certain areas, they can never have the opportunity to change their approach in this regard (Goleman, 1999). Understanding thinking styles helps individuals to understand better why some activities are appropriate for them and some are inappropriate and why this coordination exists in some individuals but not in others. Therefore, different levels of education in different educational environments require different thinking styles that can lead to better or weaker performance in different educational and occupational stages. On the other hand, the structure of emotional intelligence which has been proposed by intelligence theorists during the last decade is in fact a kind of non-cognitive intelligence which includes a set of abilities and social skills and emotion. Abilities are very important for educational success, but they are not the only influential factor because individuals' thinking styles, i.e., how they prefer to think, can be as important as whether they can think well.People with different thinking styles might be 
inclined to make use of their abilities in different ways and show different reactions according to their way of thinking. According to Goleman, people's success depends on their emotional intelligence and this ability is learnable and can be reshaped (Maurice \& Steven, 2010).

\subsubsection{Related studies}

Many domestic and international studies have focused on the relationship between emotional intelligence and students' learning or thinking styles. For instance, Ghaffari and Gholipour (2010) considered the effect of the content of courses related to the field of management on the learning style and emotional intelligence of students at the Faculty of Management, University of Tehran. They concluded that there was a positive relationship between the content of the courses and students' learning style. The hypothesis about the existence of a correlational relationship between emotional intelligence and learning style was also confirmed. The results of a study by KeshavarziArshadi et al. (2006) entitled "The effect of thinking styles and gender on emotional intelligence of students of Islamic Azad University, Tehran Central Branch" showed that there was a relationship between emotional intelligence and students' thinking styles. They found that thinking styles can predict emotional intelligence. According to them, there was a difference between boys and girls in their thinking styles, but there was no significant difference between them in emotional intelligence. Mahdavi Rad (2002) examined the relationship between creativity and thinking styles of third grade high school students in Tehran and concluded that there was a significant creativity and thinking styles in the sense that creative individuals got higher scores in judicial and legislative thinking styles which showed the integration of their interests with these two thinking styles. Besides, students with executive thinking style showed a lower level of integration with creativity; they obtained lower scores in the creativity test. Finally, they found that the students with the judicial and legislative thinking styles were affected by their fathers' occupation and those with the executive thinking style were influenced by their mothers' level of education. Tahami et al. (2001) conducted another study related to emotional intelligence and coping strategies in normal and highly intelligent students in Tehran high schools. The results of their study showed that 1) emotional intelligence of intelligent individuals is higher than that of normal individuals, 2) intelligent individuals use problem-oriented coping strategy more than the normal people, and 3) there is a correlation between emotional intelligence and use of problem-oriented coping strategy in intelligent individuals. In a different study conducted by Murphy entitled "The relationship between thinking styles and emotional intelligence: an exploratory study, Pretoria, south Africa", it was concluded that there is a meaningful relationship between thinking styles used by students when faced with problems and emotional intelligence. Furthermore, emotional intelligence of female students is higher than male ones. Zong and Sternberg (1998) considered the thinking styles of Chinese and Hong Kong students. The results of their study showed that the difference between men and women in thinking style was significant in the sense that male and female students were different in judicial, legislative, global, liberal, and inward thinking styles. In all of the styles, the scores of males was higher than females. Sternberg (1985) in his study of the relationship between thinking styles and educational performance of high school students in all areas of the United States found that there was a correlation between the legislative thinking style and creative thought (0.19) and between judicial thinking style and creative thought (0.20), and a negative correlation between the executive style and creative thought (-0.16). He also found that the correlation between judicial thinking style and creative thought was higher in male students compared to females. Austin et al. (2005) considered emotional intelligence in students of medicine and came to the conclusion that emotional intelligence of female students was considerably higher than male students. James Parker et al. (2004) investigated the relationship between emotional intelligence and academic success 
finding that the level of educational success depends to a large extent on individuals' emotional intelligence which is a determining factor in their achievement of higher levels of education.

\subsection{The present study}

As emotional intelligence has many functions as an important and influential factor in different fields such as education, occupation, making friends, curing the diseases, etc., the present study attempts to determine the relationship between emotional intelligence and thinking styles of students. This is an attempt to shed further light on the relationship between Iranian high school students' emotional intelligence and their thinking styles. As mentioned the review section, there might be differences between male and female students' emotional intelligence, but studies are few in this regard and further studies of this kind are required to establish the existence of this difference. Therefore, in this study the differences between these two sex groups in emotional intelligence and thinking styles. With regard to individuals' thinking styles, the results can help improve students' thinking and, consequently, learning style considering the fact that they can be taught and fostered in individuals. Accordingly, the following questions will be addressed in this study.

Research questions:

The main questions to be addressed in this study include:

1) is there a relationship between students' emotional intelligence and thinking style?

2 ) is there any difference between male and female students in thinking style?

3 ) is there any difference between male and female students in emotional intelligence?

\section{Method}

This study is descriptive in terms of data collection procedure and appliedin terms of goal. Field study and questionnaire were used for collecting the data. Besides, the study is survey-based because the variables were not manipulated by the researcher, but their existing measures were only described and reported. The target population included all the students at region 15 of Tehran in 2011-2012 schoolyear. The sample population included 200 (100 male and 100 female) high school students drawn from the target population. In order to determine the size of the sample, multi-stage sampling was used. First, a district (13) was randomly selected from among the school districts in Tehran. Then, from the high school students in this district, 2 were selected (a girls school and a boys school) randomly. From these two schools, 100 male and 100 female students were selected and examined. Paul's emotional intelligence questionnaire was used for collecting data. This questionnaire was initially developed in 2000 in Sydney to measure the level of emotional intelligence and was translated into Persian by Sharifian in 2000. This questionnaire has 20 questions with two options. Question 18 was eliminated because of its lack of correspondence with the Iranian culture. Sternberg and Wagner's thinking styles questionnaire was used to collected related data about students' thinking styles. This questionnaire has 40 questions that measure five thinking styles. 24 questions are related to performance and 16 questions concern different aspects of thinking styles. Overall, it includes five subtests with 8 questions related to thinking styles (judicial, legislative, liberal, outward, inward, executive).The collected data were analyzed using descriptive and inferential statistics in SPSS software. Frequency, mean, and standard deviation were used to determine the statistical features of the two (male and female) groups based on the variables under study. Inferential statistics such as Pearson correlation coefficient, Chi 2, dependent samples t-test were used to test out the research hypotheses of the study. In order to ensure validity, the questionnaire was administered to 30 participants (15 male and 15 
female) and reliability was found to be 0.78 . Sternberg and his colleagues have done comprehensive studies related to validity of thinking styles questionnaires. Reliability coefficient of the questionnaire was estimated by administering it to 75 university students. Reliability of the subtests ranged from 0.56 for the executive style to 0.88 for the global style with the mean of 0.78.validity of the questionnaire was confirmed by two university professors.

\section{Results}

Pearson correlation coefficient and chi2 were used to find the answer to the first question (see Table 1 for the results). As shown in Table 1, the results confirm the existence of a meaningful relationship between emotional intelligence and thinking styles: based on the results, the five thinking styles have a meaningful relationship with emotional intelligence.

Table 1.

The relationship between students' emotional intelligence and thinking style

\begin{tabular}{lccccccc}
\hline \multicolumn{1}{c}{ Variable } & No. & Chi 2 & df & Sig. & $\begin{array}{c}\text { Pearson } \\
\text { correlation } \\
\text { coefficient }\end{array}$ & Sig. \\
$\begin{array}{l}\text { The relationship between executive } \\
\text { style and emotional intelligence }\end{array}$ & 200 & 45.20 & 6 & 0.001 & -0.267 & 0.068 \\
$\begin{array}{l}\text { The relationship between judicial } \\
\text { style and emotional intelligence }\end{array}$ & 200 & 33.94 & 6 & 0.001 & -0.235 & 0.07 \\
$\begin{array}{l}\text { The relationship between } \\
\begin{array}{l}\text { legislative style and emotional } \\
\text { intelligence }\end{array}\end{array}$ & 200 & 52.343 & 6 & 0.001 & 0.11 & 0.073 \\
$\begin{array}{l}\text { The relationship between inward } \\
\text { style and emotional intelligence }\end{array}$ & 200 & 76.68 & 6 & 0.001 & 0.059 & 0.075 \\
$\begin{array}{l}\text { The relationship between outward } \\
\text { style and emotional intelligence }\end{array}$ & 200 & 21.55 & 6 & 0.001 & -0.181 & 0.070 \\
\hline
\end{tabular}

Besides, based on the Pearson correlation coefficient, there is a positive relationship between the legislative and inward thinking styles and emotional intelligence and executive and outward thinking styles are negatively correlated with emotional intelligence in the sense that with an increase in the inward and legislative thinking styles, there will be also an increase in emotional intelligence, but when there is an increase in executive, judicial, and outward thinking styles, emotional intelligence will decrease.

Independent samples t-test was conducted to consider the possible difference between male and female students' emotional intelligence (see Table 2). The results were indicative of the existence of a significant difference between male and female students in emotional intelligence; girls obtained higher scores in emotional intelligence compared to boys. 
Table 2 .

T-test for comparing male and female students' emotional intelligence

\begin{tabular}{ccccccc}
\hline Variable & Students & Mean & Std. & df & t & $\mathrm{p}$ \\
\hline Emotional & Male & 6.84 & 1.82 & 198 & 3.2 & 0.002 \\
intelligence & Female & 7.85 & 2.56 & & &
\end{tabular}

In order to find out if there was any difference between male and female students in thinking styles, another independent samples t-test was conducted (see Table 3).

Table 3.

T-test results for difference between males and females in thinking styles

\begin{tabular}{llccccc}
\hline Variable & Group & Mean & Std. & df & $\mathrm{t}$ & $\mathrm{p}$ \\
\hline Executive style & Males & 5.03 & 1.41 & & & \\
& Females & 5.38 & 0.97 & 198 & 2.035 & 0.43 \\
Legislative style & Males & 5.02 & 1.25 & & & \\
& Females & 5.6 & 1.05 & 198 & 3.47 & 0.001 \\
Judicial style & Males & 4.54 & 1.05 & & & \\
& Females & 5.18 & 0.98 & 198 & 5.36 & 0.001 \\
Inward style & Males & 4.72 & 1.38 & & & \\
& Females & 5.21 & 0.85 & 198 & 3.06 & 0.003 \\
Outward style & Males & 31.31 & 6.87 & & & \\
& Females & 38.07 & 5.84 & 198 & 6.8 & 0.0001 \\
\hline
\end{tabular}

Overall, the results were again indicative of meaningful differences between the two sex groups. The results of analysis showed that females obtained higher scores in thinking style compared to males.

\section{Discussion and conclusion}

Based on the results, there is a meaningful relationship between students' emotional intelligence and their thinking styles. In the legislative and inward thinking styles, this relationship was positive, but the relationship between the executive, judicial, and outward thinking styles and emotional intelligence was found to be negative. In other words, if legislative and inward thinking styles of the students are improved, emotional intelligence will also be enhanced. On the other hand, with an increase in executive, judicial, and outward thinking styles, emotional intelligence will decrease. The results were consistent with the findings of Austin et al. (2005), KeshavarziArshadi et al. (2006), and Houman (2001). Mayer et al. (1999) believe that there are some individuals who have an inclination fororgive in to bad temper easily. Some are deeply endorsed in their feelings and have no control over their emotional life. They make no attempt to get rid of their bad mental state. They often have a sense of inability and feelbroken and their feelings are uncontrollable. Sternberg (1985) states that options in our life require a correspondence between thinking styles and abilities.According to him, people do not have one thinking style but many and different thinking styles used in different situations which change during the life. 
The results of the present study also showed that there are meaningful differences between boys and girls in emotional intelligence; girls obtained higher scores in emotional intelligence compared to boys. This result is consistent with the findings of Murphy (2006) but inconsistent with Zandi (2000), KeshavarziArshadi et al. (2006). Finally, it was found that there were meaningful differences between male and female students in thinking styles. This result confirms the findings of KeshavarziArshadi et al. (2006), Emamipour (2001), Zong and Sternberg (1998), and Shokri et al. (2006). Considering the importance of this issue, authorities are recommended to review and take into consideration students' emotional intelligence and their thinking styles in order to improve the educational programs targeted at them. Considering the teachability and learnability of emotional intelligence, teacher training programs could take measures to emphasize different aspects of emotional intelligence and educate teachers in this regard so that they can inform their students of the existence of thinking and learning styles and emphasize the importance of these stylesin understanding how they can learn better and more effectively. This can help improve the efficiency and quality of education. The results can also help to improve teachers' method of teaching, and add to their knowledge about their students' emotional reactions preparing the ground for identifying abilities, talents and limitations of individuals. In this way, teachers can help them improve and make progress as a student or in the society. This can lead students to improve their emotional skills and achieve their educational goals and help to educate and improve emotional intelligence in individuals or assist students in knowing themselves, controlling their emotions, and managing their relationships with others.

Future studies could be directed at indentifying effective thinking styles by considering the relationship between students' thinking styles and their educational success. In this way, interesting empirical results can be obtainedwith regard to the efficiency of thinking styles and their effect on learning and prediction of students' future success. Sternberg (1995) believes that certain factors such as gender, culture, and school days potentially influence our thinking styles. Therefore, future studies could also focus on the effect on these factors on individuals' thinking styles.

\section{References}

Austin, E.J., Evans, P., Goldwater, R. \& Potter, V. (2005).A preliminary study of emotional intelligence, empathy and exam performance in first year medical students.Personality and Individual Differences, 39(8), 1395-405.

Emamipour, S. \&Seif A.A. (2003). Evolutionary examination of thinking styles in school and university students and their relationship with creativity and educational promotion.

Educational Innovations Quarterly, 2(3), 35-56.

Ghaffari, R. \&Gholipour, A. (2010).An investigation into the effect of the content of the courses of management on the learning style and emotional intelligence of students of the Faculty of Management at University of Tehran.Journal of Management of Organizational Culture, 8, 115-126.

Goleman, D. (1995). Emotional intelligence. $1^{\text {st }}$ ed. Bantam: New York.

Goleman, D. (2000). Emotional intelligence.Translated byBalouch, H. Keihoun Publications: Tehran.

Goleman, D. (2010). Emotional Intelligence.Translated byParsa, N. Roshd Publications: Tehran.

Goleman, D. (2011).Working with Emotional Intelligence.Random Hose Pub:NY. 
Golman, D., (2006). Social Intelligence: The New Science of Human Relationships. Bantam Books:New York.

Haghani, F., Aminian, B., \&Tahereh, C. (2011). Do teachers who are great from their students' perspective have higher emotional intelligence? Iranian Journal of Medical Education Development Center, 8(2), 132-140.

Houman, H.A. (2001).Analysis of Multi-Variable Data in Behavioral Research.Parsa Publications: Tehran.

KeshavarziArshadi, F., Emamipour, S., \&MazaheriKolahroudi, M. (2006). The effect of thinking styles and gender on emotional intelligence of students of Islamic Azad University, Tehran Central Branch.Journal of Applied Psychology, 2, 36-48.

Mahdavi Rad, H. (2002). The relationship between creativity and thinking styles of high school students of Arts in Tehran.MA thesis.Islamic Azad University, Tehran Central Branch, Faculty of Psychology.

Maurice J. E., Steven E. T.Raising Emotionally Intelligent Teenagers. Translated by Kavousi, F.: Roshd Publications: Tehran.

Mayer, J.D., Caruso, D.R.\&Salovey, P.(1999).Emotional intelligence meets traditional standards for an intelligence.27 (4), 267. 294.

Moshtaghzadeh, R. (2003). The relationship between emotional intelligence and strategies for dealing with depression in 7-to-11-year-old children.MA thesis.Islamic Azad University, Tehran Central Branch, Faculty of Psychology.

Murphy, A. (2006). The relationship between thinking styles and emotional intelligence: an exploratory study.MAThesis.Pretoria, south Africa.

Parker, J.D.A., Summerfeldt, L.J., Hogan, M.J., \&Majeski S.A. (2004).Emotional intelligence and academic success: Examining the transition from high school to university.Personality and Individual Differences, 36(1),163-72.

Sakaki, R. (2002). The relationship between emotional intelligence and personality, growth, and social adjustment factors in university students in Tehran. MA thesis.Islamic Azad University, Tehran Central Branch, Faculty of Psychology.

Salovey, P., \& Mayer, J.D. (1990).Emotional intelligence.Journal ofImagination, Cognition and Personality, 9, 185-211.

Sharifian, H. (2000).Theories and tests of intelligence and personality tests.Sokhan Publications: Tehran.

Shokri, O., Kadivar, P., Farzad, V. \&Daneshvarpour, Z. (2006). The relationship between thinking styles and approaches to learning and students' educational promotion.Journal of Innovations in Cognitive Science, 8(2), 44-52.

Sternberg, R.J. \&Grigorenko, E. L.(1995).Styles of Thinking in the School.European Journal of High Ability, 6, 201-219.

Sternberg, R.J. \&Smith,C.(1985).Social intelligence and decoding Skills in nonverbal communication.Social Cognition,168-192.

Sternberg, R.J. \& Williams, W.M.(1997). Does the graduate record examination predict meaningful success in the graduate training of psychologists? A case study.American Psychologist, 52, 630-641.

Sternberg,R.J. (2001). Thinking styles.Translated byAhari, A.E. \&khosravi, A.A. Dadar Publications: Tehran. 
Tahami, M. (2001).An investigation into emotional intelligence and coping strategies in normal and highly intelligent high school students in Tehran.MA thesis.Islamic Azad University, Tehran Central Branch, Faculty of Psychology.

Wechsler, D. (1945). A standardized memory scale for clinical use.Journal of Psychology, 19, 87-95.

Zandi, E. (2000). Considering the distribution of emotional intelligence scores of male and female students of Islamic Azad University.MA thesis, Islamic Azad University. Tehran Central Branch, Faculty of Psychology.

Zarean, M., AsadAllahpour, A., \&BakhshipourRoudsari, A. (2007).The relationship between emotional intelligence and problem-solving strategies and general health.IranianJournal of Psychiatry and Clinical Psychology, 13(2), 166-172.

Zong,L.F. \& Sternberg,R.J.(1998).Thinking Styles,Abilities and Academic achievement among HongKong university students.Hong Kong Education Research Association, 13, 41-62. 